\title{
Incidence of mortality due to rebound toxicity after 'treat and release' practices in prehospital opioid overdose care: a systematic review
}

\author{
Jennifer Anne Greene, ${ }^{1,2}$ Brent J Deveau, ${ }^{1,3}$ Justine S Dol, ${ }^{1}$ Michael B Butler ${ }^{1}$
}

\begin{abstract}
Additional material is published online only. To view please visit the journal online (http://dx.doi.org/10.1136/ emermed-2018-207534).

${ }^{1}$ Dalhousie University, Halifax, Canada

${ }^{2}$ Emergency Health Services, Halifax, Canada

${ }^{3}$ Canadian Armed Forces, Halifax, Canada
\end{abstract}

\section{Correspondence to} Jennifer Anne Greene, Dalhousie University, Halifax NS B3H 4R2, Canada; j.greene@dal.ca

Received 6 February 2018 Revised 24 October 2018 Accepted 2 December 2018 Published Online First 22 December 2018
Check for updates

(C) Author(s) (or their employer(s)) 2019. No commercial re-use. See rights and permissions. Published by BMJ.

To cite: Greene JA,

Deveau BJ, Dol JS,

et al. Emerg Med J

2019:36:219-224

\begin{abstract}
Introduction Death due to opioid overdose was declared a public health crisis in Canada in 2015. Traditionally, patients who have overdosed on opioids that are managed by emergency medical services (EMS) are treated with the opioid antagonist naloxone, provided ventilatory support and subsequently transported to hospital. However, certain EMS agencies have permitted patients who have been reversed from opioid overdose to refuse transport, if the patient exhibits capacity to do so. Evidence on the safety of this practice is limited. Therefore, our intent was to examine the available literature to determine mortality and serious adverse events within 48 hours of EMS treat and release due to suspected rebound opioid toxicity after naloxone administration.
\end{abstract}

Methods A systematic search was performed on 11 May 2017 in PubMed, Cochrane Central, Embase and CINHAL. Studies that reported on the outcome of patients treated with prehospital naloxone and released at the scene were included. Analyses for incidence of mortality and adverse events at the scene were conducted. Risk of bias and assessment of publication bias was also done.

Results 1401 records were screened after duplicate removal. Eighteen full-text studies were reviewed with seven selected for inclusion. None were found to be high risk of bias. In most studies, heroin was the source of the overdose. Mortality within 48 hours was infrequent with only four deaths among 4912 patients $\{0.081 \%$ in the seven studies. Only one study reported on adverse events and found no incidence of adverse events from their sample of 71 released patients.

Conclusion Mortality or serious adverse events due to suspected rebound toxicity in patients released on scene post-EMS treatment with naloxone were rare. However, studies involving longer-acting opioids were rare and no study involved fentanyl.

\section{INTRODUCTION}

Drug-induced mortality has reached a public health crisis status $^{12}$; overdose deaths now exceed motor vehicle collisions as a preventable cause of death in the USA. ${ }^{3}$ In Canada, there has been a $79.2 \%$ increase in illicit drug-related death in British Columbia (BC) alone between 2015 and 2016. The recent introduction of more powerful opioids, such as fentanyl, to recreational use is an acute cultural shift compounding the existing problem of opioid overdoses. ${ }^{4}$ Death from fentanyl overdose was declared a public health crisis in Canada
Key messages

What is already known on this subject

- We knew opioid overdoses were on the rise. Illicit drug deaths have increased 6.87 times that of 2010 since the introduction of synthetic opioids.

- We knew that use of emergency medical services (EMS) for care of opioid overdose was increasing; in some services estimated at over 75\% increase since 2012.

- Given the overall rise in emergency services use, we reviewed the literature to determine whether treat and release at the scene is safe.

What this study adds

- In this systematic review of seven studies that reported mortality after naloxone administration by EMS and release at the scene, we found very low incidence of mortality $\{0.081 \%)$, suggesting the safety of this practice.

- The data are limited as to largely involving overdoses from heroin, a short-acting agent. It is not clear if this data can generalise to methadone. Our findings may be more generalisable to the more recent epidemic of fentanyl abuse, because of the similar-short acting nature.

in September 2015. ${ }^{1}$ The BC Coroner's office reported 374 fentanyl-related deaths in $2016 .^{1}$ This is over double that which was reported in 2015 . $^{1}$

The increase in opioid use and overdoses has led to increased demands on prehospital services and emergency departments (EDs). Emergency medical services (EMS) routinely stock naloxone, an opioid antagonist which can reverse the effects of opioids by competitively binding to receptor sites. Naloxone itself is chemically similar to an opioid with superior binding affinity to opioid receptors but little to no other pharmaceutical effect. ${ }^{5}$ There are several observational studies on opioid overdose treatment approaches by EMS. ${ }^{6-16}$ Currently, most, approximately $90.6 \%$, opioid overdose patients are transported by EMS. ${ }^{17}$ The rationale for these conservative 'support and transport' approaches are to limit violent behaviour or instantaneous withdrawal symptoms that may ensue on delivery of naloxone $\mathrm{e}^{18}$ or to limit risk of rebound toxicity if naloxone used to reverse in the field. ${ }^{7}{ }^{19-21}$ The 'support and transport' approach may include a 
titrated dose of naloxone if the patient with apnoea is difficult to ventilate making oxygenation inadequate.

An approach that warrants further exploration based on emerging evidence is for EMS professionals to use a 'treat and release' approach, in which paramedics fully reverse overdoses with naloxone and monitor the patient for a short observation period before the patient makes an informed decision about transport to an ED or home. ${ }^{101214}$ However, the risks and benefits of this approach are uncertain. Studies have reported a very low incidence of rebound toxicity related to prehospital release post-naloxone administration for accidental overdose. ${ }^{9-14} \mathrm{~A}$ recent pooled analysis by Kolinsky found that 3/3875 (0.8\%) of released patients had mortality related to rebound toxicity. ${ }^{22}$ However, a rigorous systematic review, with an exhaustive methodological search of the literature and assessment of the quality of the studies provides a more reliable source of information for EMS decision-making.

We therefore conducted a systematic review to assess the incidence of mortality due to suspected rebound toxicity within 48 hours after 'treat and release' practices by EMS professionals for patients with suspected opioid overdose.

\section{METHODS}

\section{Data sources and search strategy}

A systematic search of the literature was conducted on 11 May 2017 to identify relevant articles on the incidence of mortality and adverse events associated with EMS treatment and release of opioid overdose patients. We followed Cochrane methodology. The protocol was registered with PROSPERO: registration number CRD42017067898. We searched PubMed, Cochrane Central, Embase and CINAHL using search strategies developed with the aid of a health sciences librarian and in conjunction with an experienced advanced care paramedic (ACP). We searched using the following terms using appropriate synonyms, $\mathrm{MeSH}$ headings and wildcards: 'emergency medical services', 'ambulances' 'emergencies', 'emergency medical technicians', 'paramedic', 'prehospital' 'naloxone' and 'narcotic antagonists'. No limits by date, language or age were applied. The bibliographies of the included studies were screened for additional relevant articles. A Preferred Reporting Items for Systematic Reviews and Meta-Analyses (PRISMA) tracking tool was used to aid in organising the search results. ${ }^{23}$ The full search strategy can be found in the online supplementary appendix A.

\section{Data selection}

Primary studies were included if they were conducted in a prehospital setting that investigated mortality in adult $(>16$ years) opioid overdose patients that were reversed with naloxone by EMS and subsequently refused transport to the ED or were released on scene. We included any primary study design in this review. This included but was not limited to abstracts, case studies, case series, cohorts, trials and randomised controlled trials. Secondary analysis of data, such as systematic reviews or narrative reviews, was excluded as well as were editorials, commentary or expert opinion pieces. Data from paediatrics, intentional overdoses, non-opioid overdoses, opioid overdoses treated exclusively by non-EMS practitioners or by EDs were not analysed. Our primary outcome of interest was mortality due to suspected rebound toxicity at or before 48 hours. Our secondary outcome was any adverse event due to suspected rebound opioid toxicity within 48 hours. This included any call for EMS or any ED presentation within 48 hours of the index EMS encounter.
We chose the time frame of 48 hours for two reasons: prior familiarity with the literature on this topic suggested that this was commonly studied time frame and second, when considering the half-life of even the longest acting opioids (eg, methadone), 48 hours offered a clinically representative time frame that would capture every rebound due to any possible residual opioid.

We conducted title and abstract screening using Covidence systematic review software (Veritas Health Innovation, Melbourne, Australia; available at www.covidence.org), independently with two reviewers (JAG and BJD) between 8 June and 11 July 2017. Disagreements were resolved by discussion. The same reviewers similarly assessed full texts for inclusion.

\section{Data extraction}

Reviewers JAG and BJD independently extracted data from the included full texts using a predetermined extraction form. This form was designed to collect information on study design, population demographics, EMS setting/provider, intervention, outcomes and results. Our primary outcome was 'mortality within 48 hours and secondary outcome was 'adverse event within 48 hours'. Data on route, dose and culprit opioid were also extracted. Abstraction discrepancies were resolved via discussion. Risk of bias was evaluated using a modified Quality in Prognostic Studies (QUIPS) tool. ${ }^{24} 25$ We selected this tool a priori due to its ability to address prognostic/retrospective studies with no comparisons. Studies with high risk of bias were to be excluded from analysis.

\section{RESULTS}

\section{Search yield}

The searches yielded 1649 studies. After duplicate removal, 1401 studies remained for screening at the title and abstract phase. The Covidence programme combines these stages into one. Thirty-three studies were discussed after title and abstract screening for inclusion, resulting in 18 articles reviewed as full texts (figure 1). From these, 11 items did not meet criteria for inclusion (online supplementary appendix B). One item was removed because it was an abstract of a published study and therefore was duplicate information. One study presented data as a Cox regression and HR of death after 48 hours. Several attempts were made to contact the author in order to request data before 48 hours, but no response was received;thus, we excluded this study from analysis. Two studies were in non-English languages. Both were translated as full texts and found to not assess the outcome of interest. Therefore, these two articles were also excluded. The other studies failed to meet the inclusion criteria related to design, outcome or setting. Seven studies met criteria and were included in the analysis (online supplementary appendix B). Inter-rater agreement was unity at both title/abstract and full-text review stages.

\section{Risk of bias}

Using the modified QUIPs tool, no studies were found to be high risk of bias, and thus all were included in the analysis (table 1). Despite the tool revealing no high risk of bias, we note that all but one of the studies are retrospective. The study by Heyerdahl was prospective. ${ }^{26}$ Because of this, we consider the overall quality of evidence is limited.

\section{Population}

A total of 4912 patients were included in this review. $671012-1426$ Mean age was similar in all studies with a combined mean age 


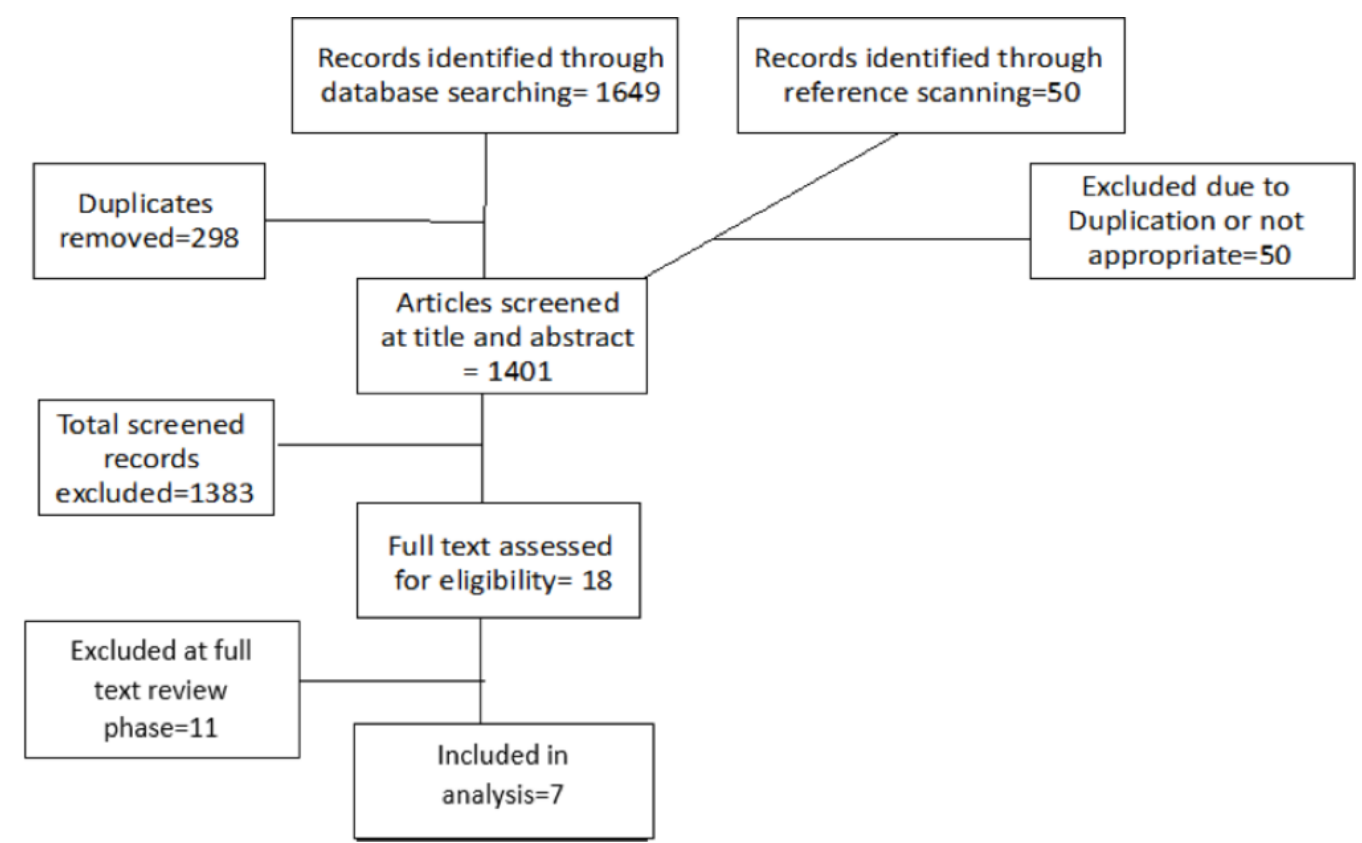

Figure 1 Preferred Reporting Items for Systematic Reviews and Meta-Analyses flow diagram of review process and results.

of 36.0 years $(\mathrm{SD}=5.48)$ (in some cases mean was estimated from the median). Females made up $20.4 \%$ of the combined patient population. All seven studies reported on prehospital opioid overdose patients treated with naloxone by a crew with at least one EMT/paramedic present (table 2). Three studies were conducted in Scandinavia and the other four were in California and Texas. Two studies were set in a fire-based system. Two other studies had a paramedic/doctor crew configuration: one in Oslo and the other Copenhagen. ${ }^{1026}$ All studies had ACPs involved in the service: five had exclusively ACPs, two had a basic and ACP combination.

\section{Control groups and interventions}

Our intervention of interest was treatment with naloxone by EMS with subsequent release, regardless if by refusal or meeting criteria for a protocol driven release on scene. All studies investigated this intervention by retrospective chart review. Two studies were conducted within services with policies delegating specific criteria for discharge on scene post-naloxone treatments. Both of these studies were Scandinavian with a paramedic/doctor configuration. Five other studies reported on patients that had refused transport against medical advice. ${ }^{6712-14}$
Three studies had comparisons to patients transported to hospital. These transported patients may be inherently different: these patients may not have responded well to the naloxone, may be suicidal or may be suffering from a multisubstance overdose. We did not aim to address these comparisons in this current review.

Several naloxone dosing regimens were used for treatment. Most dosing was at the clinician's discretion within the parameters of $0.8 \mathrm{mg}-2.0 \mathrm{mg}$ with additional doses when required. One study reported a lesser median dose of $0.4 \mathrm{mg} .{ }^{6}$ Route of administration was most commonly intravenous and/or intramuscular with two studies including the intranasal route. ${ }^{70}$ The primary culprit opioid was heroin. In two studies, methadone and possible morphine use were reported. ${ }^{10} 14$

\section{Outcomes}

Of the 4912 patients who were included in this review, four $(0.081 \%)$ died within 48 hours. The medical examiner's office (MEO) in all cases determined the official cause of death. The time frame in which the outcome follow-up occurred varied from 12 hours to 1 week, although the most commonly used time frame

Table 1 Risk of bias for included studies

\begin{tabular}{|c|c|c|c|c|c|c|}
\hline Author (year) & $\begin{array}{l}\text { Goal: to judge } \\
\text { the risk of } \\
\text { selection bias }\end{array}$ & $\begin{array}{l}\text { Goal: to judge } \\
\text { the risk of } \\
\text { attrition bias }\end{array}$ & $\begin{array}{l}\text { Goal: to judge the } \\
\text { risk of measurement } \\
\text { bias related to how } \\
\text { PF was measured }\end{array}$ & $\begin{array}{l}\text { Goal: to judge the } \\
\text { risk of bias related to } \\
\text { the measurement of } \\
\text { outcome }\end{array}$ & $\begin{array}{l}\text { Goal: to judge the } \\
\text { risk of bias due to } \\
\text { confounding }\end{array}$ & $\begin{array}{l}\text { Goal: to judge the risk } \\
\text { of bias related to the } \\
\text { statistical analysis and } \\
\text { presentation of results }\end{array}$ \\
\hline Levine et $a l^{7}$ & Low & $\mathrm{N} / \mathrm{A}$ & Low & Low & Low & Low \\
\hline Boyd et al ${ }^{6}$ & Low & $\mathrm{N} / \mathrm{A}$ & Low & Low & Low & Low \\
\hline Rudolph et al ${ }^{10}$ & Low & $\mathrm{N} / \mathrm{A}$ & Low & Low & Moderate & Low \\
\hline Vilke et $a l^{12}$ & Low & $\mathrm{N} / \mathrm{A}$ & Low & Low & Low & Low \\
\hline Vilke et $a l^{13}$ & Low & $\mathrm{N} / \mathrm{A}$ & Low & Low & Moderate & Low \\
\hline Wampler et al ${ }^{14}$ & Low & $\mathrm{N} / \mathrm{A}$ & Low & Low & Moderate & Low \\
\hline Heyerdahl et $a l^{26}$ & Low & Low & Low & Moderate & High & Low \\
\hline
\end{tabular}

N/A, Not applicable. 
Table 2 Summary of characteristics for included studies

\begin{tabular}{|c|c|c|c|c|c|c|c|c|c|}
\hline Study & Setting & $\begin{array}{l}\text { Mean age of } \\
\text { EMS patients } \\
\text { (years) }\end{array}$ & $\begin{array}{l}\text { n, EMS } \\
\text { treatment } \\
\text { group }\end{array}$ & $\begin{array}{l}\% \\
\text { female EMS } \\
\text { patients }\end{array}$ & Culprit opioid & Intervention & $\begin{array}{l}\text { Primary } \\
\text { outcome }\end{array}$ & $\begin{array}{l}\text { Secondary } \\
\text { outcome }\end{array}$ & $\begin{array}{l}\text { Deaths } \\
\text { within } \\
48 \text { hours }\end{array}$ \\
\hline Levine $e t a l^{7}$ & $\begin{array}{l}\text { US } \\
\text { EMS/LAFD }\end{array}$ & 41 & 205 & 13 & Heroin & $\begin{array}{l}\text { Naloxone with } \\
\text { release }\end{array}$ & $\begin{array}{l}\text { Death within } \\
24 \text { hours }\end{array}$ & $\begin{array}{l}\text { Death with in } \\
30 \text { days }\end{array}$ & 1 \\
\hline Boyd et al ${ }^{6}$ & Helskinki EMS & 26 & 71 & 17.2 & Heroin & $\begin{array}{l}\text { Naloxone with } \\
\text { release }\end{array}$ & $\begin{array}{l}\text { Death within } \\
12 \text { hours }\end{array}$ & Rebound toxicity & 0 \\
\hline Rudolph et $a l^{10}$ & $\begin{array}{l}\text { Copenhagen } \\
\text { MECU }\end{array}$ & - & 2241 & - & Heroin/morphine & $\begin{array}{l}\text { Naloxone with } \\
\text { release }\end{array}$ & $\begin{array}{l}\text { Death within } \\
48 \text { hours }\end{array}$ & $\begin{array}{l}\text { Death likely to } \\
\text { rebound toxicity }\end{array}$ & 3 \\
\hline Vilke et $a l^{9}$ & $\begin{array}{l}\text { US } \\
\text { EMS/SDFD }\end{array}$ & 39.8 & 317 & 16.3 & Heroin & $\begin{array}{l}\text { Naloxone with } \\
\text { release }\end{array}$ & $\begin{array}{l}\text { Death within } \\
12 \text { hours }\end{array}$ & $\mathrm{N} / \mathrm{A}$ & 0 \\
\hline Vilke et $a l^{13}$ & $\begin{array}{l}\text { US } \\
\text { EMS/SDFD }\end{array}$ & 37.7 & 998 & 16.7 & Heroin & $\begin{array}{l}\text { Naloxone with } \\
\text { release }\end{array}$ & $\begin{array}{l}\text { Death within } \\
12 \text { hours }\end{array}$ & $\mathrm{N} / \mathrm{A}$ & 0 \\
\hline Wampler et $a l^{14}$ & US EMS/SAFD & 38 & 552 & 28 & Heroin/methadone & $\begin{array}{l}\text { Naloxone with } \\
\text { release }\end{array}$ & $\begin{array}{l}\text { Death within } \\
48 \text { hours }\end{array}$ & $\begin{array}{l}\text { Death with in } \\
30 \text { days }\end{array}$ & 0 \\
\hline Heyerdahl et $a^{26}$ & $\begin{array}{l}\text { Oslo EMS, } \\
\text { outpatient clinic } \\
\text { and ED }\end{array}$ & 34 & 528 & 31 & Heroin & $\begin{array}{l}\text { Naloxone with } \\
\text { release }\end{array}$ & $\begin{array}{l}\text { Death due to } \\
\text { rebound in } \\
1 \text { week }\end{array}$ & N/A & 0 \\
\hline
\end{tabular}

ED, emergency department; EMS, emergency medical service; LAFD, Los Angeles Fire Department; MECU, Mobile Emergency Care Unit; SAFD, San Antonio Fire Department; SDFD, San Diego Fire Department. N/A, not applicable.

to assess mortality was 12 hours (table 1 ). Levine observed one death within 24hours with a MEO reported cause of death as 'coronary artery disease and heroin' ${ }^{7}$ Authors reported that it was not definitively determined if this death was suspect to rebound toxicity or a possible new overdose. This finding was conservatively included in the four patients with the outcome.

Boyd also investigated altered level of consciousness suspect to rebound postrelease, finding no incidence of that outcome. ${ }^{6}$ This was the only study that reported on our secondary outcome of adverse events due to suspected rebound toxicity within 48 hours.

\section{Statistical analysis}

The incidence of the mortality outcome was so low that the assumptions necessary to perform a weighted meta-analysis could not be met (eg, normality of the observed effect sizes and weighting of the effect sizes inversely proportional to their variance). When assessing for heterogeneity, a $0.00 \% \mathrm{I}^{2}$ statistic was calculated and the Wald's test statistic showed a p value of 0.9740 ; thus, the null hypothesis of homogeneity was not rejected. When compiling the forest plot for effect size, a non-zero constant $(0.05)$ had to be artificially introduced to the zero incident cases in order to obtain a meaningful estimate (figure 2). There were zero events in most studies, thus not permitting for an overall proportion to be reported.

We assessed for publication bias using a funnel plot. None of the studies fall outside of the $95 \%$ CI. This plot does not indicate any evidence of publication bias (figure 3).

\section{DISCUSSION}

We uncovered seven studies (six retrospective and one prospective design) with no high risk of bias. The findings suggest very low risk of mortality when treat and release practices are employed by EMS providers in accidental opioid overdose. One challenge to generalising this existing evidence into practice is concerning the opioid used and its corresponding halflife. Our included studies found heroin to be the primary culprit opioid. Heroin overdose made up 445 of 5779 opioids poisonings causing hospitalisations in Canada in 2016-2017. ${ }^{27}$ The half-life of heroin is relatively short, but its metabolites, such as morphine, can have effects that last $3-5$ hours. ${ }^{28}$ The longest acting opioid, methadone, has a half-life of up to 59 hours. ${ }^{29}$ Out of 5779 opioid toxic events in Canada in 2016-2017 causing hospitalisation, 473 were due to methadone. ${ }^{27}$ This is concerning for rebound toxicity, after giving a short-acting antidote such as naloxone. Naloxone has a duration of action of $30-120 \mathrm{~min}$ with a half-life estimated at $28.2 \mathrm{~min}$, depending on the route of administration. ${ }^{50}$ However, in the studies with predominant heroin overdose, naloxone treat and release appeared safe. Synthetic opioids, such as fentanyl, are significant contributors to the current crisis and have varyingly similar pharmacokinetics to heroin. ${ }^{31}$ Heroin is less potent than fentanyl and this has led many healthcare providers to believe that a larger dose or naloxone is necessary when treating fentanyl overdose, yet this is generally not seen in practice and animal and case reports suggest otherwise. ${ }^{2832}$

The secondary outcome concerned adverse events postrelease related to suspected rebound toxicity. The intention was to investigate suspected risk factors associated with opioid reversal that may happen after the patient has been released from care

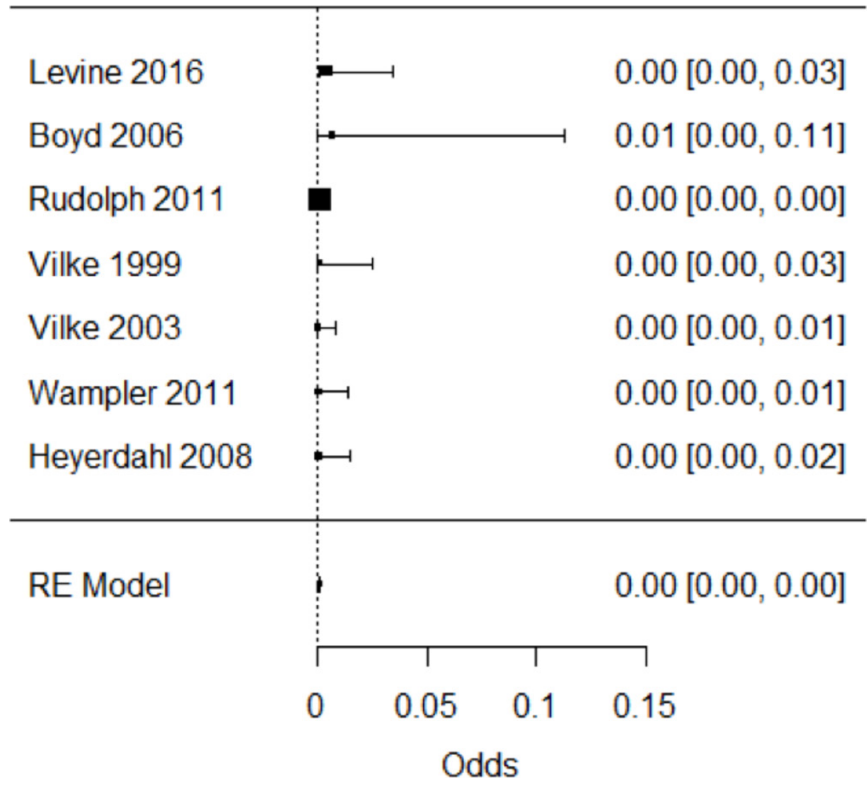

Figure 2 Plot of effect size for mortality. 


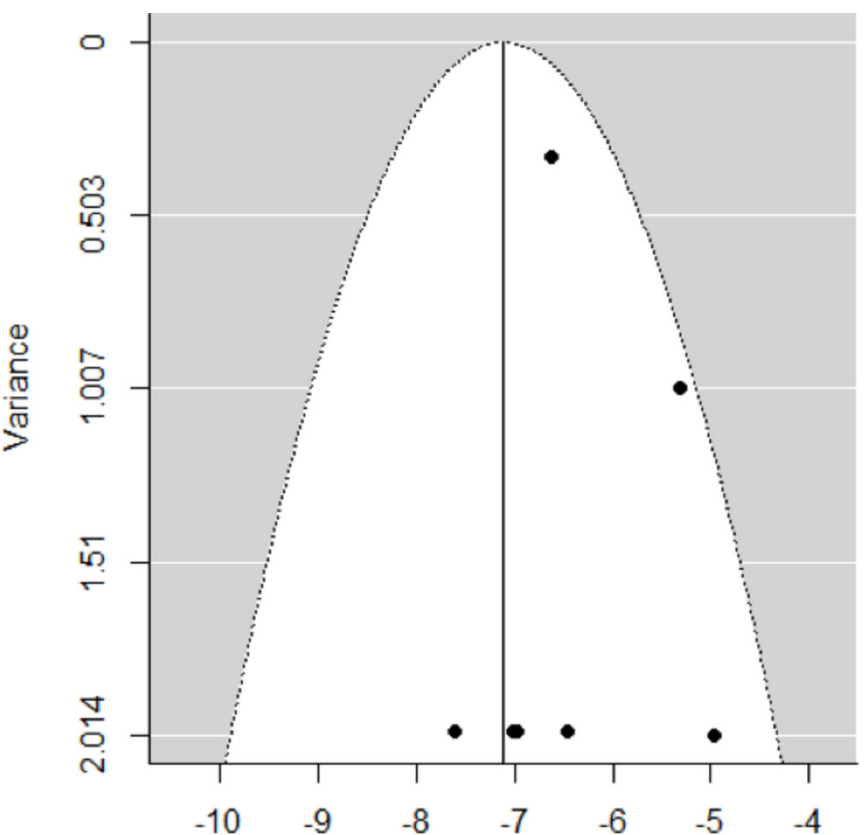

Log Odds

Figure 3 Funnel plot assessing publication bias of included studies.

such as decreased level of consciousness, hypertensive crisis or pulmonary oedema. ${ }^{683-35}$ Boyd was the only study that investigated an adverse event, decreased level of consciousness postrelease, and found no such occurrence. While not included in this review due to timing of reporting, a study by Buajordet in 2004 addressed adverse events post-naloxone treatment but only in the period immediately postadministration. ${ }^{35}$ The mean time of adverse event occurrence in this study was within $8 \mathrm{~min}$ of medication delivery and while the patient was still in EMS care. They observed adverse events in $45 \%$ of the cases related to the administration of naloxone which were mostly non-serious and primarily related to sudden withdrawal (33\%). Only three $(0.3 \%)$ cases were considered serious and hospitalised accordingly. Similarly, Osterwalder conducted a prospective study investigating the frequency and degree of adverse events post-naloxone administration. ${ }^{36}$ Six of 453 patients (1.3\%; $95 \%$ CI $0.4 \%$ to $3 \%$ ) experienced severe adverse events including one cardiac arrest, three seizures and one case of pulmonary oedema. All events occurred within 10 min of administration and none after 10 min. In a retrospective review of heroin overdoses in the ED by Smith, there were three cases of pulmonary oedema found, all within $20 \mathrm{~min}^{3}{ }^{34}$ While these immediate adverse events were not the outcome of interest, it raises the point that naloxone has its own potentially adverse effects many of which are due to rapid reversal causing sudden withdrawal and these seem to occur immediately postadministration.

The timeframe in which adverse events occur seems to be within minutes after naloxone administration. So how long should the observation time last and what criteria do paramedics use as indications for who can be safely released on scene? Some literature suggests not releasing a patient after reversal with naloxone treatment until several hours have passed, with longer durations if patient awakens from a coma. ${ }^{37}$ Christensen validated a prediction rule with a sensitivity of $99 \%(95 \%$ CI $96 \%$ to $100 \%)$ and a specificity of $40 \%$ (95\% CI $36 \%$ to $45 \%){ }^{38}$ This rule states that if a patient has been reversed from an opioid overdose with naloxone in the ED or EMS setting, they are safe to be discharged after 1 hour of observation if they meet the following criteria: (1) can mobilise as usual; (2) have oxygen saturation on room air of $>92 \%$; (3) have a respiratory rate $>10$ breaths/min and $<20$ breaths/min; (4) have a temperature of $>35.0^{\circ} \mathrm{C}$ and $<37.5^{\circ} \mathrm{C}$; (5) have a heart rate $>50$ beats/ min and $<100$ beats/min and (6) have a Glasgow Coma Scale score of 15. This length of time may not be feasible in all EMS settings but it suggests safety of the release practice. Further research is required to answer that question.

\section{Limitations}

While there are many strengths of this review, there are limitations, mainly related to the design and reporting of the included studies. All but one of the included studies were retrospective chart reviews lending to the biases and charting inconsistencies inherent to this design. Most of the studies state that they could not account for a death or adverse event outside the catchment area of their protocol. The potentially illegal and stigmatised nature of this clinical situation may lead to patients providing aliases or inaccurate information. However, measures were taken in all cases to mitigate this potential. There were also some missing data, most of which were from the Rudolph study in which 1517 of 4762 patients remained unidentified at follow-up. ${ }^{10}$ There was only one study that reported data on the second outcome of adverse events. However, this may be due to the fact that this outcome would be difficult to capture after the patient was released from care, particularly in a patient population that is notoriously difficult to track. Many of these studies predate the current fentanyl-related crisis and thus have limited generalisability. Prospective enrolment and rigorous follow-up would be the ideal design for this question.

\section{CONCLUSIONS}

Mortality or serious adverse events in the included studies due to suspected rebound toxicity in patients released on scene post-EMS treatment with naloxone was rare. There was very limited evidence available reporting on adverse events.

Acknowledgements The authors would like to thank Dr Jillian Hayden for supervising this systematic review; Robin Parker for her assistance in the development of our search strategy and support during the search process and Ida Zavattin and Erik Palmen for their contribution in translating the non-English studies.

Contributors JAG was the main author and initiated the idea and protocol, managed all key actions and created all first drafts. BJD was the second screener/ abstracter and contributed significantly to the pharmacology content. JSD is the senior researcher who provided guidance and recommendations throughout and aided in the data organisation and cleaning. MBB was the statistician for this project who analysed all data and created all figures. All authors contributed to draft revisions and editing content for the manuscript.

Funding The authors have not declared a specific grant for this research from any funding agency in the public, commercial or not-for-profit sectors.

Competing interests None declared.

Patient consent for publication Not required.

Provenance and peer review Not commissioned; externally peer reviewed.

Data sharing statement Additional data can be provided upon request to corresponding author.

\section{REFERENCES}

1 Coroners Service B. Ministry of Public Safety and Solicitor General Fentanyl-Detected Illicit Drug Overdose Deaths. 2012. https://www2.gov.bc.ca/assets/gov/public-safetyand-emergency-services/death-investigation/statistical/fentanyl-detected-overdose.pdf (cited 19 Dec 2017).

2 Cash RE, Kinsman J, Crowe RP, et al. Naloxone administration frequency during emergency medical service events - United States, 2012-2016. MMWR Morb Mortal Wkly Rep 2018;67:850-3. 
3 Mack KA. Centers for Disease Control and Prevention (CDC). Drug-induced deaths United States, 1999-2010. MMWR Supp/ 2013;62:161-3.

4 National Post. B.C. declares public health emergency after fentanyl overdoses kill 200 people in three months. http://nationalpost.com/news/canada/b-c-declares-publichealth-emergency-after-fentanyl-overdoses-kill-200-people-in-three-months (cited 22 Dec 2017).

5 Drugs.com. Naloxone hydrochloride monograph for professionals. https://www.drugs. com/monograph/naloxone-hydrochloride.html (cited 22 Dec 2017).

6 Boyd JJ, Kuisma MJ, Alaspää A0, et al. Recurrent opioid toxicity after pre-hospital care of presumed heroin overdose patients. Acta Anaesthesio/ Scand 2006;50:1266-70.

7 Levine M, Sanko S, Eckstein M. Assessing the risk of prehospital administration of naloxone with subsequent refusal of care, 2017:3127.

8 Osterwalder JJ. Patients intoxicated with heroin or heroin mixtures: how long should they be monitored? Eur J Emerg Med 1995;2:97-101.

9 Moss ST, Chan TC, Buchanan J, et al. Outcome study of prehospital patients signed out against medical advice by field paramedics. Ann Emerg Med 1998;31:247-50.

10 Rudolph SS, Jehu G, Nielsen SL, et al. Prehospital treatment of opioid overdose in Copenhagen-is it safe to discharge on-scene? Resuscitation 2011;82:1414-8.

11 Stokland O, Hansen TB, Nilsen JE. Prehospital behandling av heroinforgiftning i Oslo i 1996. Tidsskr den Nor Laegeforening 1998;118:3144-6.

12. Vilke GM, Buchanan J, Dunford JV, et al. Are heroin overdose deaths related to patient release after prehospital treatment with naloxone? Prehosp Emerg Care 1999;3:183-6.

13 Vilke GM, Sloane C, Smith AM, et al. Assessment for deaths in out-of-hospital heroin overdose patients treated with naloxone who refuse transport. Acad Emerg Med 2003;10:893-6.

14 Wampler DA, Molina DK, McManus J, et al. No deaths associated with patient refusal of transport after naloxone-reversed opioid overdose. Prehosp Emerg Care 2011;15:320-4.

15 Watson WA, Steele MT, Muelleman RL, et al. Opioid toxicity recurrence after an initial response to naloxone. J Toxicol Clin Toxicol 1998;36:11-17

16 Willman MW, Liss DB, Schwarz ES, et al. Do heroin overdose patients require observation after receiving naloxone? Clin Toxicol 2017;55:81-7.

17 Faul M, Lurie P, Kinsman JM, et al. Multiple naloxone administrations among emergency medical service providers is increasing. Prehosp Emerg Care 2017;21:411-9.

18 Clarke SF, Dargan PI, Jones AL. Naloxone in opioid poisoning: walking the tightrope. Emerg Med J 2005;22:612-6.

19 Seidler D, Woisetschlaeger C, Schmeiser-Rieder A, et al. Prehospital opiate emergencies in Vienna. Am J Emerg Med 1996;14:436-9.

20 Yealy DM, Paris PM, Kaplan RM, et al. The safety of prehospital naloxone administration by paramedics. Ann Emerg Med 1990;19:902-5.

21 Sporer KA. Acute heroin overdose. Ann Intern Med 1999;130:584-90.
22 Kolinsky D, Keim SM, Cohn BG, et al. Is a prehospital treat and release protocol for opioid overdose safe? J Emerg Med 2017;52:52-8.

23 Moher D, Shamseer L, Clarke M, et al. Preferred reporting items for systematic review and meta-analysis protocols (PRISMA-P) 2015 statement. Syst Rev 2015:4:1.

24 Hayden JA, van der Windt DA, Cartwright JL, et al. Assessing bias in studies of prognostic factors. Ann Intern Med 2013:158:280-6.

25 Biases Issues to consider for judging overall rating of Risk of bias Study Methods Comments Rating of reporting Rating of Risk of bias. http://methods.cochrane.org/ sites/methods.cochrane.org.prognosis/files/public/uploads/QUIPS tool.pdf (cited 4 Jan 2018).

26 Heyerdahl F, Hovda KE, Bjornaas MA, et al. Pre-hospital treatment of acute poisonings in Oslo. BMC Emerg Med 2008;8:1-9.

27 Canadian Institute for Health Information. Opioid-related harms in Canada. 2017 https://secure.cihi.ca/free_products/opioid-harms-chart-book-en.pdf (cited 22 Dec 2017).

28 Olson KR. Poisoning \& drug overdose. 2012 http://accessmedicine.mhmedical.com/ book.aspx?bookid=391.

29 Universal Free E-Book Store. Gilman\%27s the pharmacological basis of therapeutics. 12th edn. http://freepages.school-alumni.rootsweb.ancestry.com/ dpok/Goodman (cited 22 Dec 2017).

30 Vanky E, Hellmundt L, Bondesson U, et al. Pharmacokinetics after a single dose of naloxone administered as a nasal spray in healthy volunteers. Acta Anaesthesiol Scand 2017;61:636-40.

31 Centre on Substance Abuse CDeaths Involving Fentanyl in Canada, 2009-2014: CCENDU Bulletin. 2009 www.ccsa.ca (cited 22 Dec 2017).

32 Moresco A, Larsen RS, Sleeman JM, et al. Use of naloxone to reverse carfentanil citrate-induced hypoxemia and cardiopulmonary depression in Rocky Mountain wapit (Cervus elaphus nelsoni). J Zoo Wildl Med 2001;32:81-9.

33 Wermeling DP. Review of naloxone safety for opioid overdose: practical considerations for new technology and expanded public access. Ther Adv Drug Saf 2015;6:20-31.

34 Smith DA, Leake L, Loflin JR, et al. Is admission after intravenous heroin overdose necessary? Ann Emerg Med 1992;21:1326-30.

35 Buajordet I, Næss A, Jacobsen D, et al; Adverse events after naloxone treatment of episodes of suspected acute opioid overdose, 1999:19-23.

36 Osterwalder JJ. Naloxone-for intoxications with intravenous heroin and heroin mixtures - harmless or hazardous? A prospective clinical study. J Toxicol Clin Toxicol 1996;34:409-16.

37 UpToDate. Acute opioid intoxication in adults. https://www.uptodate.com/contents/ acute-opioid-intoxication-in-adults (cited 2017 Dec 22).

38 Christenson J, Etherington J, Grafstein $\mathrm{E}$, et al. Early discharge of patients with presumed opioid overdose: development of a clinical prediction rule. Acad Emerg Med 2000;7:1110-8. 